\title{
The Semantic Learning Organization
}

\author{
Miguel-Ángel Sicilia \\ Computer Science Department, University of Alcalá \\ Ctra. Barcelona km. 33600 - 28871 Alcalá de Henares (Madrid) SPAIN \\ msicilia@uah.es
}

\author{
Miltiadis D. Lytras \\ Athens University of Economics and Business \\ Department of Management Science and Technology \\ ELTRUN - The Research Center \\ 47A Evelpidon Str., 11362 Athens, Greece \\ mdl@eltrun.gr
}




\title{
The Semantic Learning Organization
}

\begin{abstract}
The application of "Semantic Web" technologies to learning processes is receiving an increasing attention from the perspective of facilitating the selection, delivery and tailoring of learning experiences. But most of the current approaches are centered on the final interaction of the learner with the "learning objects" provided for him/her, neglecting the organizational perspective. From the viewpoint of an organization, the application of Semantic Web technologies should be motivated by the improvement of learning-oriented mechanisms, including both cultural and structural aspects, and considering the ideal of achieving a state of continuous improvement in learning behavior. Such an approach to achieving a "semantic learning organization" gives a complementary perspective to existing "educational Semantic Web" propositions. In this paper, the potential role of the Semantic Web as a driver for enhanced learning organizations is analyzed, and a conceptual framework for the notion of a semantic learning organization is provided.
\end{abstract}

Keywords: E-learning, ontologies, Semantic Web, organizational learning, learning organization. 


\section{The "Semantic" Learning Organization}

\section{Introduction and Background}

The concept of learning organization is used to refer to a particular type of organization, which can be considered as an ideal form of system in which learning behavior improves and adapts, and in which a concrete climate facilitates the learning of individuals, and managers are supposed to be coaches instead of directors (Örtenblad, 2001). This vision contrasts to "old" organizational learning views in which the knowledge is considered to reside in the company, mainly in the form of procedures, rules, and others means for shared representation. While a learning organization is usually defined as a form of organization, organizational learning is considered as the set of actual learning activities or processes inside the organization. According to Reynolds and Ablett (1998), the learning organization is characterized for a change in the behavior of the organization itself as a result of learning.

If the learning organization is considered as something that needs effort to be carried out, as stated by Örtenblad, it turns out that certain kinds of technology can be considered as better drivers or facilitators for achieving the status of learning organization. Current learning technology can be used to effectively manage the delivery of courses through the Web, and also their administration and assessment. In fact, the evolution of specifications and standards for learning technology has fostered consistency among software vendors and content providers, and specifications like SCORM ${ }^{1}$ deal with aspects of standardized sequencing of learning activities and contents.

Nonetheless, a higher degree of "intelligence" would be desirable to achieve an ideal state in which learning processes are mediated by software that targets and delivers just-in-time the learning activities that are required by the individuals as a response to personal growth and customer needs fulfillment. The research areas of intelligent tutoring systems (ITS) and adaptive hypermedia $(\mathrm{AH})$ have produced a considerable amount of techniques and tools - based on diverse Artificial Intelligence approaches - that enable such degree of advancement in learning activities (Brusilovsky, 2000). But most of ITS and AH work has been developed as domain or problem-dependent implementations, so that it takes a big effort to transfer the research outcomes to practical implementations. This has raised the search for open intelligent infrastructures, ready to be used with standard Internet technology. A recent proposition for such a kind of open infrastructure for "intelligence" is the so-called Semantic Web.

The "Semantic Web" vision described by Berners-Lee et al (2001) has resulted in a considerable amount of research and development initiatives that have in common the focus on extending current Web technology with machine-understandable metadata, aimed at providing layered services. Such services are able to exploit the semantics provided by metadata descriptions to implement advanced, "intelligent" services that expand the current capabilities of Web technology. Formal ontologies (Gruber, 1991) play an essential role in the Semantic Web

\footnotetext{
${ }^{1} \mathrm{http}: / /$ www.adlnet.org
} 
vision, since they provide the shared conceptualizations expressed in logical form that can be used by software agents to act on behalf of humans in search processes or distributed activities. In other words, ontologies provide metadata the shared semantics that enable interoperable intelligent agents. Some previous research has addressed the topic of ontologies as part of learning systems - a review can be found in (Lytras, Tsilira, \& Themistocleous, 2003).

If we analyze some of the essential mechanisms that are consider being facilitators for the emergence of a learning organization (Armstrong \& Foley, 2003), it can be stated that Semantic Web technology is a potential catalyst for learning organizations. Table 1 summarizes the opportunities opened by Semantic Web technologies for the four categories of organizational learning mechanisms described by Armstrong \& Foley. It should be noted that the issues described in Table 1 complement existing views of the "Educational Semantic Web" with an organizational perspective. The educational semantic Web has emerged as a research agenda that is currently focused on the final learner-system interaction, but that largely neglects the perspective that individual learning somewhat transfers to collective and to organizational or inter-organizational, and vice-versa. Nonetheless, the organizational and educational views do not compete but complement, since the latter addresses important issues that include activitybased learning, modeling of pedagogies, and consistency in metadata profiles among others.

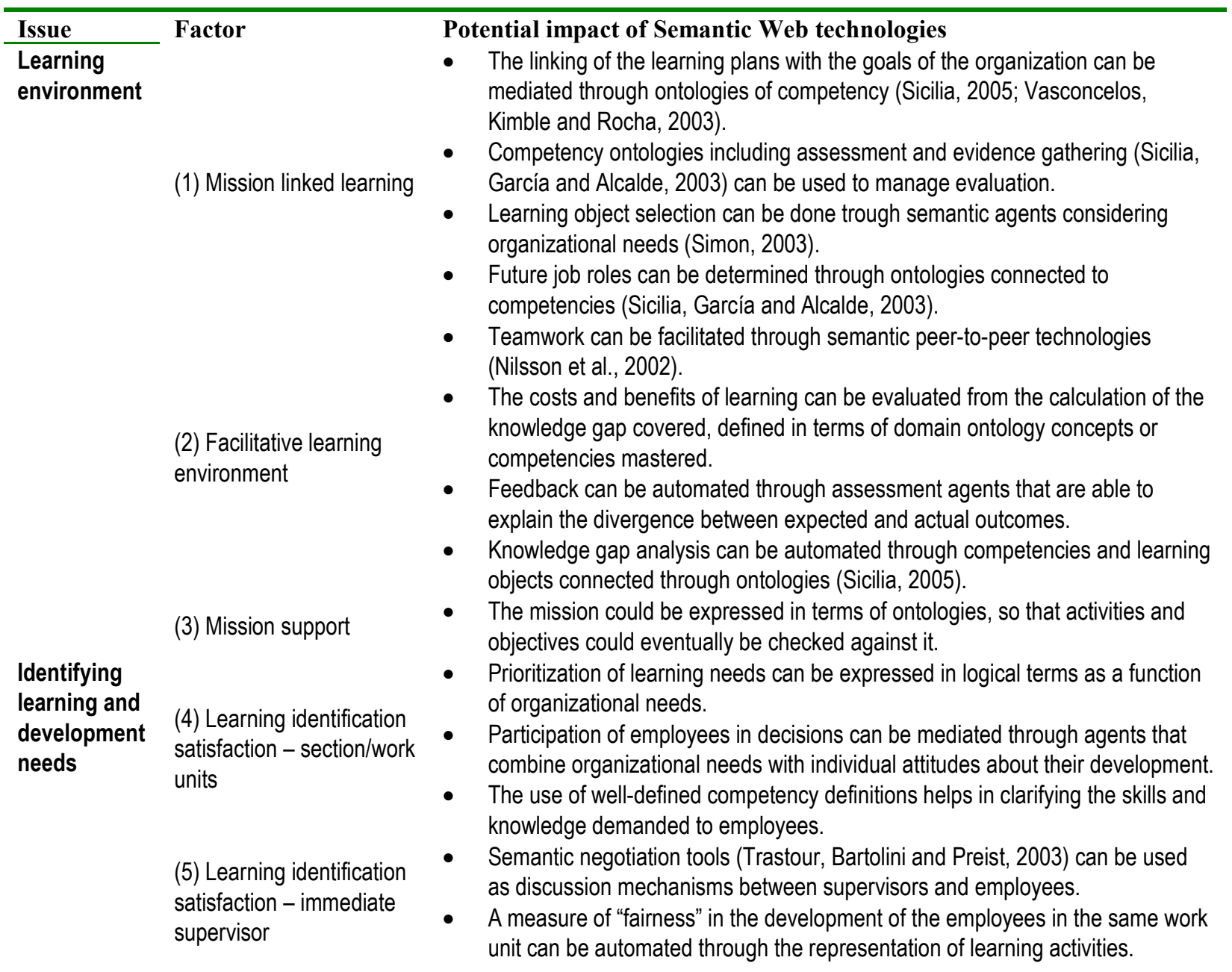




\author{
Meeting \\ learning and \\ development \\ needs
}

(6) Organization support

(7) Low personal impact

(8) Mentoring and coaching

(9) Training satisfaction

Applying learning in the workplace
(10) Learning application suitability

(11) Learning application effectiveness

(12) Learning application

- immediate supervisor support and feedback
- $\quad$ The scheduling and calendar restrictions to deliver activities can be controlled by agents (Payne, Singh and Sycara, 2002).

- Semantically related simultaneous activities can be identified with the purpose of joining the employees engaged in them in informal groups.

- Semantic tools can be used to locate activities that are relevant to the needs of an employee (García \& Sicilia, 2003).

- The semantic representation of learning activities as triggered by business needs can be used to build "explanation" tools.

- Automated workload assessment can be used to prevent disadvantages or situation of stress for employees.

- Mentors and coaches can be semantically selected by matching the profiles of people inside the company.

- Learning styles can be represented as part of the ontologies, so that the selection of learning experiences takes them into account (McCalla, 2004).

- $\quad$ Sharing of knowledge and experiences of learning can be mediated by semantic software tools.

- Employees can inspect their own record of learning.

- Comparisons of products and services can be provided.

- The ontology representation of job situations and episodes enables the checking that the learning outcomes are actually put into practice.

Table 1. Potential impact of Semantic Web technologies on organizational learning mechanisms

As can be notice when examining Table 1, ontology-based competency management plays a central role in organizational learning. The availability of detailed competency ontologies is one of the cornerstones of the semantic approach to organizational processes. A tentative schema for such kind of ontology is described by Sicilia (2005), and the specifications of the HrXML consortium $^{2}$ also provide basic interoperability. Nonetheless, much work is still required in competencies in the context of the Semantic Web, and such area should receive a special attention from the perspective of organizational learning and learning organization approaches.

The issues briefly described in Table 1 are applications of Semantic Web technologies that could be implemented with the existing state of technology, as described, for example, by Simon et al (2004). Nonetheless, there exists still a higher level of intelligence that should be considered as the objective for a learning organization, i.e. the facilitation of change in the behavior of the organization as a result of changes in the individuals, which requires some kind of self-reflective capabilities. The following section deals with this idea, and some of its possible realizations.

\section{The Concept of a Semantic Learning Organization}

The "Semantic Learning Organization" (SLO) is a concept that extends the notion of learning organization in the technological dimension, so that a semantic learning organization can be considered as a learning organization in which learning activities are mediated and enhanced through a kind of technology that provides a shared knowledge representation about the domain

\footnotetext{
${ }^{2}$ http://www.hrxml.org
} 
and context of the organization. Although Semantic Web technology can not be considered as a requirement for every possible approach to a learning organization, at least in knowledgeintensive organizations, shared semantics provide a competitive advantage when oriented to value inside organizational processes (Lytras, Pouloudi \& Poulymenakou, 2002).

Extending the definition proposed by Sun and Scott (2003), a SLO can be characterized as "Where semantics-mediated learning takes place that moves the organization to a desired state". The important point of this definition as opposed to organizational learning is that learning "must" result in changes in behavior. In consequence, Semantic Web technology should be applied not only to enhance learning processes, but as a purposeful tool to drive changes in behavior. This is an unambiguous research and development objective for the Semantic Web that has still not be approached in existing systems and tools. Semantics is understood here as the result of using shared ontologies to provide metadata with a rich knowledge-based infrastructure. Metadata encompasses not only the description of learning objects, but also the definition of organizational mission, objectives and resources, the specification of competencies and other information that could be required for the mechanisms described in Table 1.

Some of the issues that have to be covered for such evolutionary view of learning are summarized in Table 2.

\begin{tabular}{ll}
\hline Issues & Example semantic tools and services \\
\hline Encouragement to innovation and entrepreneurship. & $\begin{array}{l}\text { Personalized information delivery about organizational } \\
\text { needs depending on the competency and interest of the } \\
\text { employees. } \\
\text { Repositories of ideas and suggestions that are } \\
\text { automatically connected to business or individual needs } \\
\text { and objectives. } \\
\text { The formal representation of the mission allows for the } \\
\text { connection of the mission statement to activities. Tools } \\
\text { can use such specification for a matter of providing } \\
\text { awareness to employees. } \\
\text { A notion of employee feedback can be represented } \\
\text { inside the ontology, resulting in proactive actions to } \\
\text { gather feedback, and draw conclusions about the } \\
\text { specific climate in work units. } \\
\text { Changes in the business environment can be detected } \\
\text { through changes in product and services offerings in the } \\
\text { context of semantic business intelligence tools that use } \\
\text { ontologies to have a coherent view of the environment. } \\
\text { Decision making can be informed by gathering relevant } \\
\text { information for the decision at hand by using ontologies } \\
\text { as the link between organization-wide information } \\
\text { repositories. }\end{array}$ \\
& \\
\hline
\end{tabular}

Table 2. Some issues that should be addressed for the ideal of a semantic learning organization.

The main problem about the SLO is the development of assessment tools that obtain a figure of the current learning behavior of the organization. Without such characterization, it is impossible to purposely catalyze a change in learning behavior. Such overall assessment may come from 
analysis processes of the volume, effectiveness, efficiency and satisfaction of current learning processes, but at the best of our knowledge, no intelligent system has attempted to obtain such kind of global judgment. A substitute of an automated assessment of that kind could be a wise combination of data mining regarding learning activities and outcomes, combined with decisionsupport tools that help top management in the processes of decision making that drive changes in learning behavior. Semantic Web technologies can be especially useful in the processes of sensemaking and decision-making as part of the organizational knowing cycle described by Wei Choo (2001). In both cases, the implicit connections between information (being external or internal) provided by ontologies give an opportunity to build software tools that gather all the relevant information for the perception of change or decision at hand.

It should be noted that the SLO will not come without a cost, just as a learning organization is considered to require effort (Örtenblad, 2001). In the following section, some of the main challenges for a SLO are discussed.

\section{Challenges for the emergence of Semantic Learning Organizations}

Once the vision for a SLO is stated, it comes the time to provide a realistic account of its technical and cultural feasibility. Extending the ideas of García \& Sicilia (2004), Table 3 summarizes the main obstacles of the implementation of the Semantic vision as a specialized learning organization.

\begin{tabular}{|c|c|}
\hline Obstacle & Description and forces \\
\hline $\begin{array}{l}\text { Creation and maintenance of shared } \\
\text { representations. }\end{array}$ & $\begin{array}{l}\text { The creation and maintenance of large, shared conceptualizations is a } \\
\text { problem in itself, which should be approached both from the perspective of } \\
\text { ontology engineering and also from the viewpoint of standardization. Since } \\
\text { ontologies are socially constructed artifacts, they evolve with time, entailing } \\
\text { significant maintenance costs (van Elst and Abecker, 2002). }\end{array}$ \\
\hline $\begin{array}{l}\text { Availability and evolution of } \\
\text { advanced tools. }\end{array}$ & $\begin{array}{l}\text { Semantic tools for learning, collaboration and communication require an } \\
\text { extra effort of development than normal Web tools, since they use underlying } \\
\text { languages like description logics (Baader et al., 2003) that are often arcane } \\
\text { for the average practitioners. The selection of development libraries and } \\
\text { frameworks thus become a critical point. }\end{array}$ \\
\hline $\begin{array}{l}\text { Increase in the workload due to } \\
\text { increasing needs for metadata. }\end{array}$ & $\begin{array}{l}\text { The approach described is metadata-intensive, since episodes and activities } \\
\text { inside the company need to be annotated in order to be used by semantic } \\
\text { agents. }\end{array}$ \\
\hline $\begin{array}{l}\text { Alignment of organizational and } \\
\text { individual needs. }\end{array}$ & $\begin{array}{l}\text { The coherence between organizational and individual needs and priorities is } \\
\text { a problem that is difficult to address, since it encompasses the continuing } \\
\text { measure of employee satisfaction, and the fit of learning activities taking into } \\
\text { account such satisfaction. This could result in conflicts if not carefully } \\
\text { addressed. }\end{array}$ \\
\hline
\end{tabular}

Given the actual state of Semantic Web technology, the recommended path for organizations that are committed to the view of a SLO is that of first addressing infrastructural elements. Such infrastructures can be considered as the study and provision of the ontologies for each aspect of the SLO, and beginning the constructions of prototypes as drivers for the seamless adoption of 
the semantic view. Concretely, competencies and their ontological representation can be considered as a critical point in any Semantic approach to a learning organization.

\section{Conclusions}

Semantic Web technologies provide a semantic infrastructure that enables the enhancement of organizational learning processes and mechanisms. Existing Semantic Web technology can be applied to provide some degree of "intelligence" to existing search, location and targeting of learning activities, among other processes. Assessment of such activities can also be mediated by software that exploits shared knowledge representations in the form of ontologies. Nonetheless, such enhanced processes are necessary but not sufficient for the ideal of a semantics-based learning organization. The major requirements and challenges for the achievement of a Semantic Learning Organization have been described, in an attempt to shape a research agenda that integrates existing views on the "educational semantic web" with the organizational perspective.

\section{References}

Armstrong, A. and Foley, P. (2003). Foundations for a learning organization: organization learning mechanisms. The Learning Organization, 10(2), pp. 74-82.

Baader, F., Calvanese, D., McGuinness, D., Nardi, D., Patel-Schneider, P. (eds.). (2003). The Description Logic Handbook. Theory, Implementation and Applications, Cambridge.

Berners-Lee, T., Hendler, J., Lassila, O. (2001). The Semantic Web. Scientific American, 284(5), pp. 34-43.

Brusilovsky, P. (2000) Adaptive hypermedia: From intelligent tutoring systems to Web-based education (Invited talk). In: G. Gauthier, C. Frasson and K. VanLehn (eds.) Intelligent Tutoring Systems. Lecture Notes in Computer Science, Vol. 1839, Berlin: Springer Verlag, pp. 1-7.

García, E. \& Sicilia, M.A. (2003). User Interface Tactics in Ontology-Based Information Seeking . Psychnology e-journal 1(3):243-256.

Gruber, T.R. (1993). A translation approach to portable ontologies. Knowledge Acquisition, 5(2), pp. 199-220.

Lytras, M., Tsilira, A. \& Themistocleous, M.G. (2003). Towards the semantic e-Learning: an ontological oriented discussion of the new research agenda in e-Learning. In Proceedings of the Ninth Americas Conference on Information Systems, pp. 2985-2997.

Lytras, M., Pouloudi, A., \& Poulymenakou, A. (2002). Dynamic e-Learning setting through advanced semantics: The value justification of a knowledge management oriented metadata schema. International Journal of e-Learning, 1(4), 49-61. 
McCalla, G. (2004). The Ecological App roach to the Design of E-Learning Environments: Purpose-based Ca p t $\mathrm{u}$ re and Use of Information About Learners. Journal of Interactive Media in Education, 2004 (7).

Nilsson, M. \& Palmér, M. \& Naeve, A. (2002). Semantic Web Meta-data for e-Learning - Some Architectural Guidelines. In Proceedings of the 11th World Wide Web Conference, Hawaii, May 7-11.

Örtenblad, A. (2001). On differences between organizational learning and learning organization. The Learning Organization, 8(3), pp. 125-133.

Payne, T.R., Singh, R. and Sycara, K. (2002). Calendar Agents on the Semantic Web. IEEE Intelligent Systems, 17(3), pp. 84-86.

Reynolds, R. and Ablett, A. (1998). Transforming the rhetoric of organizational learning to the reality of the learning organization. The Learning Organization, 5(1), pp. 24-35.

Sicilia, M.A. and García, E. (2004). On the Convergence of Formal Ontologies and Standardized e-Learning. Journal of Distance Education Technologies 2(4).

Sicilia, M. A., García, E., Alcalde, R. (2003). Fuzzy Specializations and Aggregation Operator Design in Competence-Based Human Resource Selection. In Proceedings of the 8th World Federation on Soft Computing Conference, Springer.

Sicilia, M.A. (2005). Ontology-Based Competency Management: Infrastructures for the Knowledge-intensive Learning Organization. In: Lytras and Naeve (Eds.): Intelligent Learning Infrastructures in Knowledge Intensive Organizations: A Semantic Web perspective. IDEA, USA (to appear, 2005).

Simon, B. (2003). Learning Object Brokerage: How to make it happen. In: Proceedings of EdMedia 2003, pp. 681-688.

Simon, B., Dolog., P., Miklós, Z., Olmedilla, D. and Sintek, M. (2004). Conceptualising Smart Spaces for Learning. Journal of Interactive Media in Education, 2004(9).

Sun, P. and Scott, J. (2003). Exploring the divide - organizational learning and learning organization. The Learning Organization 10(4), pp. 202-215.

Trastour, D., Bartolini, C. and Preist, C. (2003). Semantic Web support for the business-tobusiness e-commerce pre-contractual lifecycle. Computer Networks 42(5), pp. 661-673.

Vasconcelos, J., Kimble, C. and Rocha, A. (2003). Organisational Memory Information Systems: An Example of a Group Memory System for the Management of Group Competencies. Journal of Universal Computer Science, 9(12). 
Van Elst, L. and Abecker, A. (2002). Ontologies for information management: balancing formality, stability, and sharing scope. Expert Systems with Applications, 23(4), pp. 357366.

Wei Choo, C. (2001). The knowing organization as learning organization. Education+Training, 43(4/5), pp. 197-205. 